\title{
Urban Thermal Influence on the Background Environment of Convective Precipitation
}

\author{
Hirofumi SUGAWARA \\ Earth and Ocean Sciences, National Defense Academy of Japan, Yokosuka, Japan \\ Ryoko ODA \\ Civil and Environmental Engineering, Chiba Institute of Technology, Chiba, Japan \\ and \\ Naoko SEINO \\ Meteorological Research Institute, Tsukuba, Japan
}

(Manuscript received 30 November 2016, in final form 18 August 2017)

\begin{abstract}
Does the presence of cities enhance precipitation? It is an issue that needs to be addressed. This study focuses on the thermal excess in cities and attempts to determine the influence of this parameter on atmospheric instability, which constitutes the background condition for convective precipitation. A simple analytical approach involving the calculation of the daytime evolution of the mixed layer over a homogeneous ground surface was developed. The calculations were based on the data from the ensemble average of observations. Using these calculations, the convective available potential energy (CAPE) was obtained for two idealized geographic areas: one with urban land cover and the other with rural land cover. Urban heat excess, which was $200 \mathrm{~W} \mathrm{~m}^{-2}$ greater than rural area, increased CAPE value by $75 \%$ comparing to the rural CAPE value of $513 \mathrm{~J} \mathrm{~kg}^{-1}$. Cities can produce stratification in the atmosphere that is favorable for convective precipitation.
\end{abstract}

Keywords urban heat island; convective available potential energy; convective precipitation

\section{Introduction}

The question of whether the existence of cities can cause increased precipitation has been a long-running climatological debate. However, to date, there is no satisfactory answer to this question. A recent review by Shepherd (2005) summarized the evidence in support of the influence of urban locales on precipi-

Corresponding author: Hirofumi Sugawara, Earth and Ocean Sciences, National Defense Academy of Japan, 1-10-20 Hashirimizu, Yokosuka, Kanagawa 239-8686, Japan E-mail: hiros@nda.ac.jp

J-stage Advance Published Date: 21 December 2017 tation. However, additional factors besides the urban environment have prevented the clear determination of the influence of the urban setting on precipitation. For example, Shepherd et al. (2002) used satellite data for Atlanta, Georgia, USA to examine the influence of this urban area on precipitation. Commenting on the results reported by Shepherd et al. (2002), Diem et al. (2004) suggested that the precipitation in Atlanta is probably influenced by the 150 m.a.s.l. mountains that are located $110 \mathrm{~km}$ from the city.

Some cities in Japan are located in areas with terrain that is more complex than Atlanta; therefore, the urban and topographical effects on precipitation must 
be separated. The following review picked up some observational studies for Japan, particularly in the Tokyo. All studies that were reviewed herein focused on convective precipitation during the summer. Inoue and Kimura (2004) analyzed the available satellite data for the wider Tokyo region and found that there was a relatively high frequency of low-altitude clouds present over Japanese cities. They also found that line-type cloud formations occurred along the arterial roads (Inoue et al. 2004). In a similar study on the convective precipitation, Fujibe et al. (2002) presented examples of the generation of radar echoes over regions of surface convergence in Tokyo. Kobayashi et al. (2009) found that X-band radar echoes were generated at higher altitudes over the urban areas of Tokyo in comparison with those generated over the surrounding rural area. Sato and Takahashi (2000) showed a positive trend between heavy rain and surface convergence for Tokyo on a decadal time scale. Sato et al. (2006) showed that a high frequency of radar echo was generated over the city when precipitation systems that originated in the rural mountainous areas passed over Tokyo.

Our analysis of these previously reported results revealed four dominant mechanisms that are responsible for the influence of urban areas on precipitation:

1) The activation of convection resulting from large surface sensible heat fluxes (Kusaka et al. 2014; Matheson and Ashie 2008).

2) The evaporation of anthropogenic water vapor to the atmosphere (Moriwaki et al. 2008).

3) The modification of surface wind systems resulting from the increase in surface drag (Takahashi et al. 2011).

4) The increase in condensation nuclei resulting from the presence of atmospheric pollutants (Rosenfeld and Lensky 1998).

This study focused on the thermal influence of convective precipitation in summer because it appeared to be the most influential of the listed mechanisms. This decision appeared to be supported by Senoo et al. (2004), who concluded that the excess humidity from evaporation does not influence the spatial distribution of water vapor in urban air. In addition, Rosenfeld and Lensky (1998) showed that the dynamic influence of surface wind may have a more localized effect than the other factors, and that an increase in atmospheric aerosols can have both a positive effect and a negative effect on the amount of urban precipitation.

To simplify the discussion, this study assumed a virtual flat homogeneous surface with a single land cover. Two cases were considered: 1) an urban land cover and 2) a rural or country-side land cover. These cases produced a spatial scale of a few tens of kilometers, which corresponded to the densely inhabited districts of Tokyo. We focused on the changes in atmospheric stratification, which supports the initiation of precipitation events, partially due to various land covers. Land cover influences the triggering and development of precipitation events on a fine spatial scale, whereas convection is initiated at urban boundaries and in rural areas (Ohashi and Kida 2002).

The thermal influence of cities, which is marked by a sensible heat flux larger than that for rural areas, should appear in the unstable stratification of the atmosphere. This study examined how the urban and rural land cover changes atmospheric stability indexes. The destabilization of atmospheric stratification resulting from the generation of anthropogenic water vapor was also determined. This simple analysis has not yet been performed in previous studies. Investigating the influence of an urban area on precipitation is a complex problem that encompasses many physical processes. Most previous studies have considered this complex problem in its entirety, but this study broke down this problem into its elementary processes. Although our simplified analysis does not completely answer the question "Do cities cause increased precipitation?", the following simple discussion is a start to solving this complex problem.

\section{Methodology}

\subsection{Outline}

Assuming an idealized city and a rural area whose variations are limited to the surface heat flux, the convective available potential energy (CAPE) value was determined for each type of land cover. CAPE corresponds to the buoyant energy for an air parcel and is an index used for assessing the atmospheric stability. An approximate threshold of $2000 \mathrm{~J} \mathrm{~kg}^{-1}$ or greater represents a favorable condition for the generation of convective precipitation. CAPE can be calculated as follows:

$$
\mathrm{CAPE}=-R_{d} \int_{p_{L F C}}^{p_{L N B}}\left(T_{v}-\bar{T}_{v}\right) d(\ln p),
$$

where $T_{v}$ and $\bar{T}_{v}$ are the virtual temperatures of the rising air parcel and its surrounding environment, respectively, $p$ is the air pressure, and $R_{d}$ is the gas constant for dry air. The subscripts $L N B$ and $L F C$ indicate the level of neutral buoyancy and the level of free convection, respectively. CAPE is calculated from the vertical profiles of the air temperature and water vapor. In this calculation, the virtual rising air parcel 


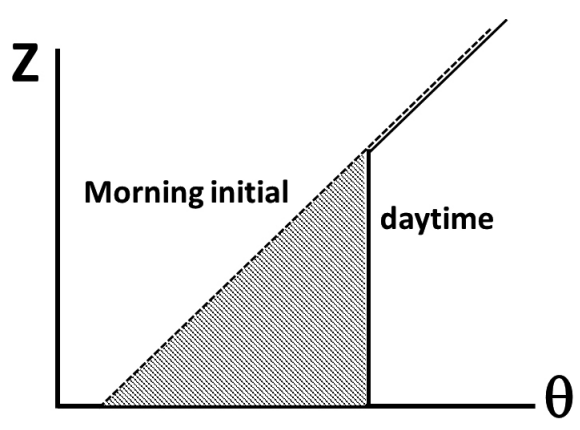

Fig. 1. Schematic of the mixed layer model. The hatched area corresponds to the accumulated surface sensible heat flux.

follows the dry adiabatic and moist lapse rates below and above the condensation level, respectively. This study employed a mixed layer model to determine the profiles reflecting the surface sensible heat fluxes for both the urban and rural areas (Fig. 1). This model assumed a profile with a constant potential temperature within the mixed layer. The increase in the height and temperature within the mixed layer was calculated from the incoming surface heat flux.

$$
\int_{0}^{z_{t}} c_{p} \rho\left(T_{i}-T_{i-1}\right) d z=\int_{t_{i-1}}^{t_{i}} Q_{H} d t
$$

where $c_{p}$ and $\rho$ are the specific heat and density of air, respectively, $z_{t}$ is the depth of mixed layer, and subscript $i$ denotes time. This model produced vertical air temperature profiles with $Q_{H}$ as the input. The parameter $z_{t}$ at time $i$ was determined from $Q_{H}$ and the temperature lapse rate above $z_{t, i-1}$. The profile of the vapor mixing ratio was also assumed to be constant in

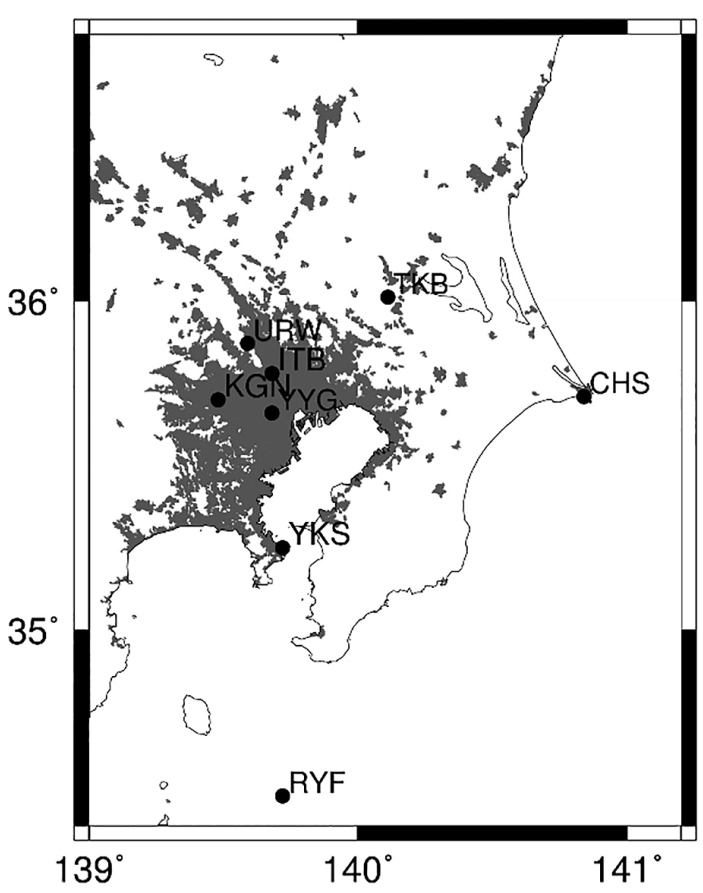

Fig. 2. Map of study sites. Location names are listed in Tables 1 and 2. Areas in gray are those that are densely populated.

the mixed layer and was calculated using the surface evaporation flux. The initial conditions at 06:00 local standard time (LST) were obtained from the observed results.

The calculated CAPE value was compared with the measured CAPE value in eight locations, as shown in Fig. 2. The details of these CAPE measurements are summarized in Table 1.

Table 1. List of sonde observations. Abbreviations for each location are provided in parentheses in the first column

\begin{tabular}{lccc}
\hline \multicolumn{1}{c}{ Location (Abbr.) } & Latitude & Longitude & Measurement period \\
\hline Choushi (CHS) & $35^{\circ} 42^{\prime} \mathrm{N}$ & $140^{\circ} 50^{\prime} \mathrm{E}$ & Aug. 2012 \\
Koganei (KGN) & $35^{\circ} 42^{\prime} \mathrm{N}$ & $139^{\circ} 29^{\prime} \mathrm{E}$ & Oct. 2011 \\
Tsukuba (TKB) & $36^{\circ} 03^{\prime} \mathrm{N}$ & $140^{\circ} 08^{\prime} \mathrm{E}$ & $\begin{array}{c}\text { Aug. }- \text { Oct. 2011 } \\
\text { Aug. }- \text { Sep. 2012 }\end{array}$ \\
& & & $\begin{array}{c}\text { Jul. }- \text { Sep. 2013 } \\
\text { Itabashi (ITB) }\end{array}$ \\
& $35^{\circ} 47^{\prime} \mathrm{N}$ & $139^{\circ} 41^{\prime} \mathrm{E}$ & $\begin{array}{c}\text { Aug. }- \text { Oct. } 2011 \\
\text { Sep. 2013 }\end{array}$ \\
Urawa (URW) & $35^{\circ} 52^{\prime} \mathrm{N}$ & $139^{\circ} 35^{\prime} \mathrm{E}$ & $\begin{array}{l}\text { Jul. and Sep. } 2013 \\
\text { Aug. }- \text { Oct. } 2011\end{array}$ \\
Yokosuka (YKS) & $35^{\circ} 15^{\prime} \mathrm{N}$ & $139^{\circ} 43^{\prime} \mathrm{E}$ & $\begin{array}{c}\text { Aug. 2012 } \\
\end{array}$ \\
& & & Jul. - Sep. 2013 \\
Research vessel Ryofu (RYF) & $34^{\circ} 20-39^{\prime} \mathrm{N}$ & $139^{\circ} 37-49^{\prime} \mathrm{E}$ & Jul. 2013 \\
\hline
\end{tabular}




\subsection{Initial conditions}

This study focused on convective precipitation during the summer in Japan, so the initial conditions of the mixed layer model were obtained from the results observed during the summer. The upper part of the initial profile (above $2 \mathrm{~km}$ ) was the average of 14 runs in the sonde observations conducted in July 2013 and September 2013. These observations were conducted in Urawa and denoted as URW in Fig. 2. The observed profiles and the initial condition are shown in Fig. 3. The lower part of the initial profile was acquired from observations obtained using the microwave radiometer at 06:00 LST. Different data sources were used for the upper and lower profiles due to the insufficient number of sonde runs made in the early morning and the limited altitude capabilities of the microwave radiometer. The two observation campaigns were conducted using a microwave radiometer. One was conducted over a rural site in Tsukuba (TKB in Fig. 2), whereas the other was over an urban site in Yoyogi (YYG). A microwave radiometer (KIPP \& ZONEN, MTP-5H) was used to measure the radiant temperature at $60 \mathrm{GHz}$ at several elevation angles, producing an air temperature profile from the surface to $600 \mathrm{~m}$. Before these campaigns, radiometer observations were validated using routine sonde observations conducted by the Japan Meteorological Agency over Tateno (near TKB). The vertical profile of the root-mean-square error (RMSE) of the radiometer for the sonde measurements is shown in Fig. 4. The RMSE was less than $1.2 \mathrm{~K}$ throughout the altitude range, and the larger RMSE that was obtained during the morning hours most likely reflected the residual nocturnal inversion layer.

The potential temperature profiles over Tsukuba and Yoyogi are shown in Fig. 5. Clear differences

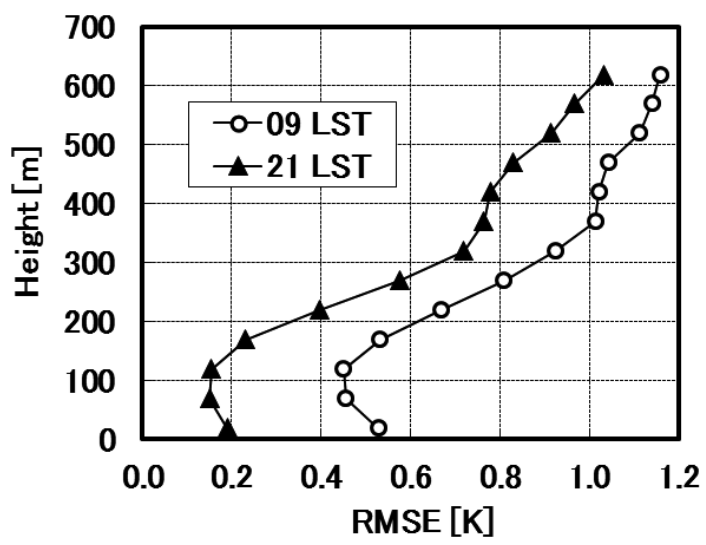

Fig. 4. Vertical profile of the root-mean-square error (RMSE) in the validation of microwave radiometer (MTP-5H) against sonde observations.
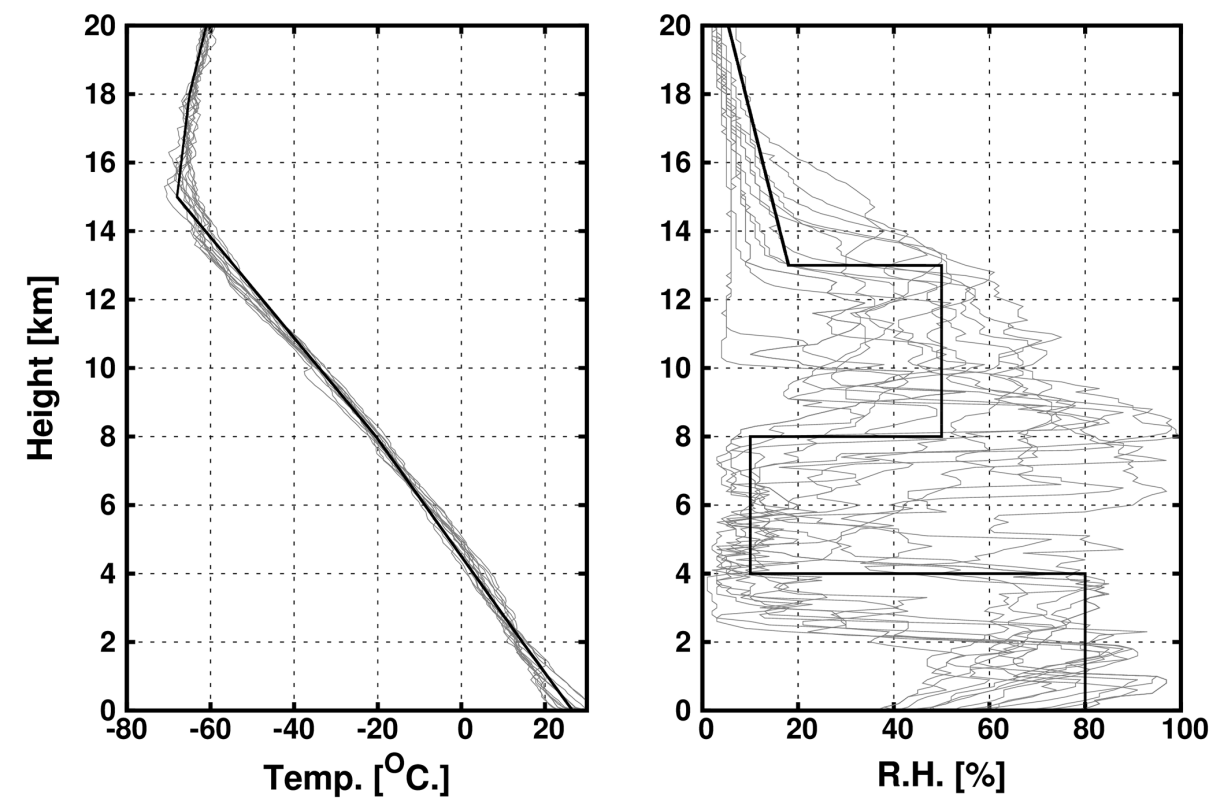

Fig. 3. Morning profiles of air temperature and relative humidity, which are used as the initial condition in the mixed layer model (black line). The thin lines represent profiles from Urawa. 
were evident in the slopes of these profiles. The steeper slopes occurred at the rural site in Tsukuba. It should be because of the lower thermal inertia over the rural ground surface (Sugawara et al. 2001). The neutral profile at the lowest $200 \mathrm{~m}$ for Yoyogi was characteristic of cities experiencing stronger boundary layer mixing due to excess heat (buoyancy) and the increased surface topographical roughness in comparison with rural areas. Considering these urban-rural differences, we used two types of initial conditions for the model in the lowest $2-\mathrm{km}$ regions. One was the urban condition in which the potential temperature gradient was $3 \mathrm{~K} \mathrm{~km}^{-1}$, referred to as the "near-neutral condition" herein. The second was the rural gradient of $8 \mathrm{~K} \mathrm{~km}^{-1}$, referred to as the "stable condition" in this study. In the case of the initial profile of water vapor, a common profile of relative humidity is shown in Fig. 3 and was applied to each of the two study cases.

\subsection{Contrast in sensible heat flux}

The surface sensible heat flux, which was the input for the mixed layer model, was acquired for three different types of land covers, as listed in Table 2. At the rural site in Tsukuba, the sensible heat flux was measured using a sonic anemometer mounted on a meteorological tower at $29.5 \mathrm{~m}$ above ground level. Within the footprint of the measured flux, the dominant land cover comprised vegetation and some low-story residential structures. At the urban (Yoyogi) and suburban (Itabashi) sites, a scintillometer (Sintec, BLS-900) was used to obtain the heat flux measurements. The scintillometer transmits and receives light at a wavelength of $880 \mathrm{~nm}$ and measures the fluctuations in the refractive index of air. The sensible heat flux was calculated based on the fluctuations in the refractive
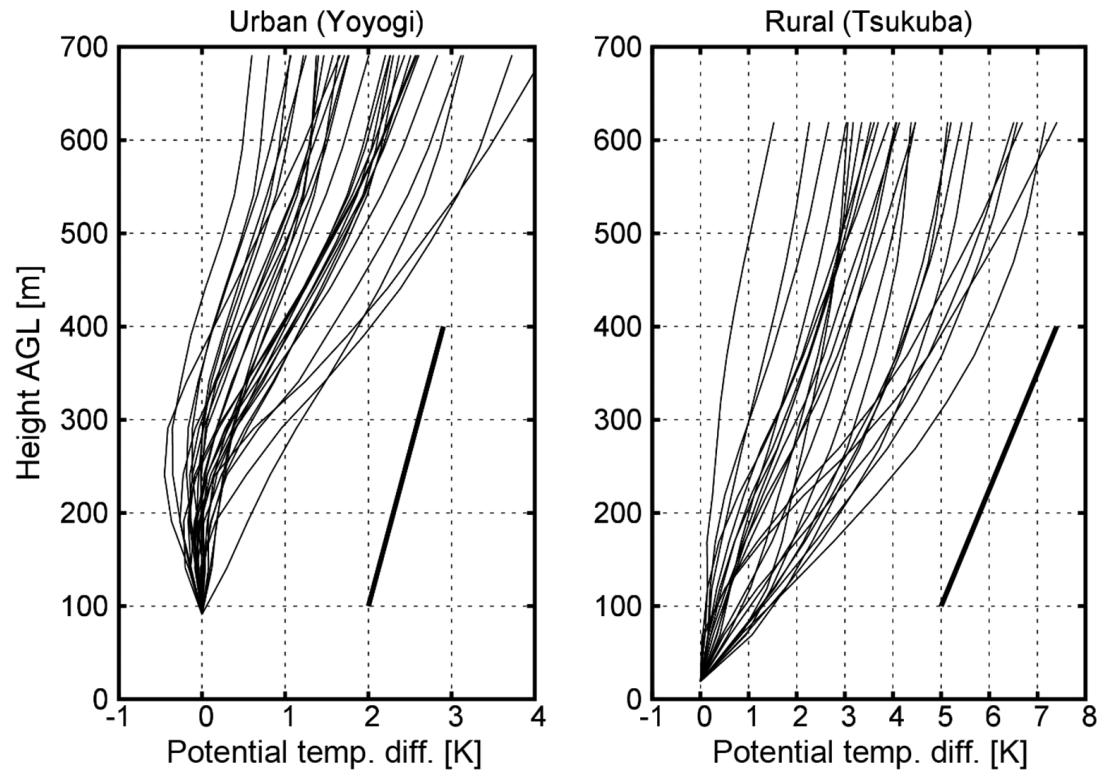

Fig. 5. Potential temperature profile relative to the lowest measurement level at 03:00 JST in summer. 10-min average from 1-min raw measurement. The rural profiles of 26 runs were measured in June 2010 and July 2010 in Tsukuba, and the urban profiles of 31 runs were measured in July 2011 and August 2011 in Yoyogi. The bold thick lines indicate the gradient of potential temperature used in the initial condition of simulation.

Table 2. Measurement sites for the surface sensible heat flux. Abbreviations for each location are provided in parentheses in the first column

\begin{tabular}{llcl}
\hline Location (Abbr) & \multicolumn{1}{c}{ Land cover } & Areal fraction of vegetation & Methodology \\
\hline Tsukuba (TKB) & Rural, low height vegetation & $74 \%$ & Eddy correlation \\
Itabashi (ITB) & Suburban, low-storied residential houses & $19 \%$ & Scintillation \\
Yoyogi (YYG) & Urban, high-storied residential houses & $2 \%$ & Scintillation \\
\hline
\end{tabular}


index using the Monin-Obukhov (MO) similarity theory. In this process, the transmitter and receiver can be located kilometers apart, and therefore, the size of the sample footprint can be larger than that used in the eddy covariance method. This larger footprint is one of the advantages of using this method for measuring the heat flux in urban heterogeneous land cover. The light path was $2.3 \mathrm{~km}$ long in Itabashi and $1.1 \mathrm{~km}$ in Yoyogi. To solve the MO equations, this study used a mixed method (Largouarde et al. 2006), which is more robust than other methods (e.g., free convection) and does not require the assumption of atmospheric stability. The mixed method requires the input of two parameters: roughness length and displacement height within the spatial footprint. We evaluated these parameters utilizing a morphometric method (Macdonald et al. 1998) with a modified canopy height, as proposed by Tanaka et al. (2011). The diurnal variation in the sensible heat flux at all three sites is shown in Fig. 6. As shown in this figure, there was an ensemble average of fair-weather days with a solar duration that exceeded $80 \%$ of the astronomically available solar duration. The anthropogenic heat flux obtained from the inventory database for Tokyo, produced by Ministry of the Environment Japan (2003), is also included in Fig. 6.

\subsection{Calculation cases}

The mixed layer model produced a vertical profile every hour from the initial 06:00 LST to noon time (12:00 LST). The CAPE values were calculated for the profile up to 12:00 LST, and eight cases were used for the simulation (Table 3 ). In cases $1-5$, the initial profile was near neutral $\left(3 \mathrm{~K} \mathrm{~km}^{-1}\right)$ in the lowest $2 \mathrm{~km}$ and stable $\left(8 \mathrm{~K} \mathrm{~km}^{-1}\right)$ in cases $6-8$. Three types of diurnal variations were used for the surface sensible heat flux: rural (case 1 and 6), suburban (case 2 and 7 ), and urban (case 3 and 8). We also employed the anthropogenic heat (case 4) and water vapor (case 5) in some calculations. The diurnal variation of these anthropogenic components was obtained from the Japanese Ministry of the Environment (2003), and the values for a $1 \mathrm{~km} \times 1 \mathrm{~km}$ area in Yoyogi were obtained from this database. The anthropogenic water vapor was found to be $18 \mathrm{~g} \mathrm{~m}^{-2}(6 \mathrm{~h})^{-1}$ in the morning hours (6:00-12:00 LST), corresponding to a latent heat flux of $2 \mathrm{~W} \mathrm{~m}^{-2}$. The rural evaporation flux was determined using the measured sensible heat flux and the Bowen ratio (sensible heat/latent heat). We used a Bowen ratio of 1.87 for the calculations, as reported by Kuwagata et al. (1990).

\section{Results}

The calculations for the CAPE at 12:00 LST are shown in Fig. 7. With regard to the effect of the variations in urban vs. rural areas on the sensible heat flux, the heat excess of the urban area (case 3 minus case 1) increased the CAPE value by $379 \mathrm{~J} \mathrm{~kg}^{-1}(74 \%$
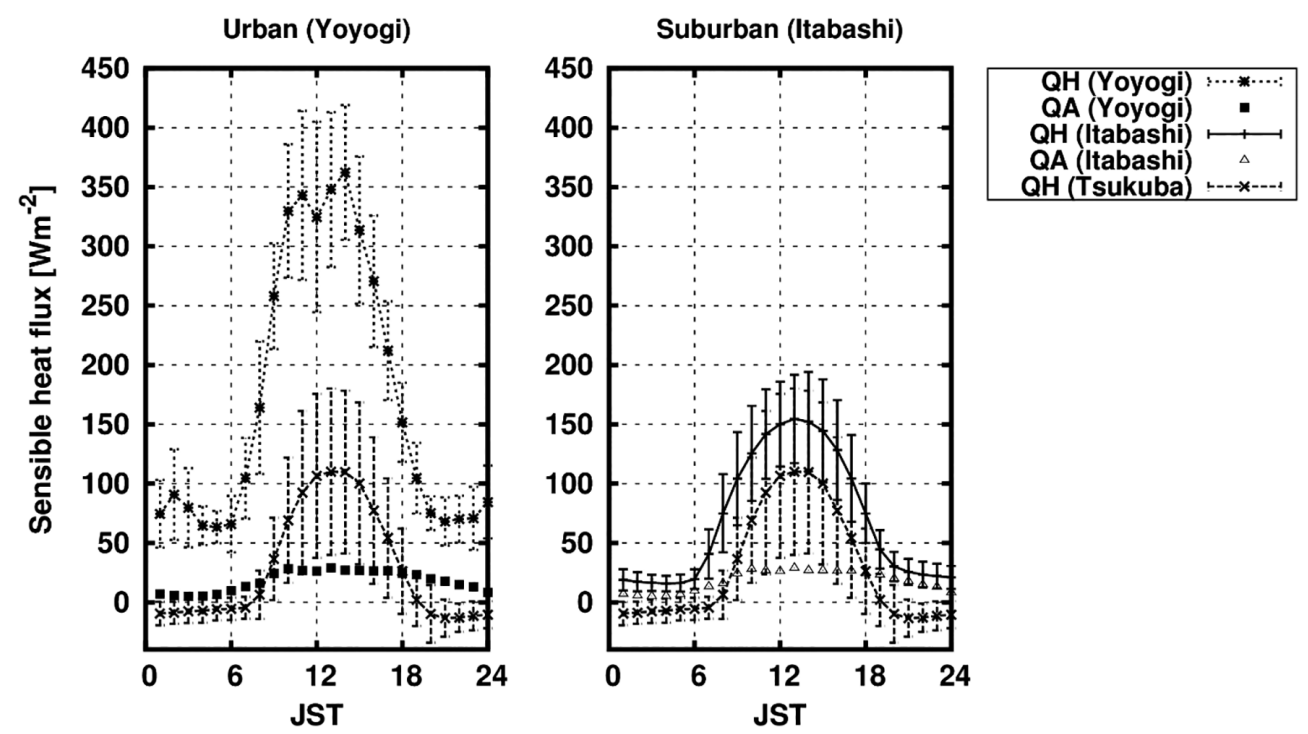

Fig. 6. Ensemble average of the surface sensible heat flux $Q_{H}$ in the urban (Yoyogi), suburban (Itabashi), and rural (Tsukuba) areas. Anthropogenic heat flux $\left(Q_{A}\right)$ is also shown for the urban and suburban areas (average of 1 $\mathrm{km} \times 1 \mathrm{~km}$ area). Additionally, rural $Q_{H}$ is shown in both panels. 
Table 3. A list of calculation cases

\begin{tabular}{ccll}
\hline No. & Initial profile & \multicolumn{1}{c}{ Heat flux } & \multicolumn{1}{c}{ Evaporation flux } \\
\hline 1 & Near neutral & Rural observation & Rural value \\
2 & Near neutral & Suburban observation & Rural value \\
3 & Near neutral & Urban observation & Rural value \\
4 & Near neutral & $\begin{array}{l}\text { Urban observation minus anthropogenic } \\
\text { comp. in Yoyogi }\end{array}$ & Rural value \\
& & Urban observation & Rural value minus anthropogenic \\
5 & Near neutral & Rural observation & Rural value \\
6 & Stable & Rugogi \\
7 & Stable & Suburban observation & Rural value \\
8 & Stable & Urban observation & Rural \\
\hline
\end{tabular}

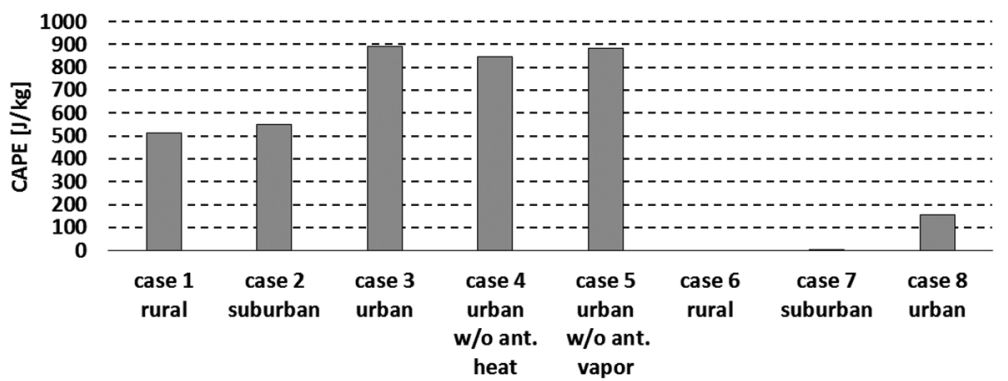

Fig. 7. Calculated convective available potential energy (CAPE) for the near-neutral initial profile (cases 1-5) and stable profile (cases 6-8). Case 4 represents the urban case without anthropogenic heat, whereas case 5 represents the urban case without anthropogenic water vapor. Note that the suburban case with a stable profile (case 7) has a CAPE value of $4 \mathrm{~J} \mathrm{~kg}^{-1}$, and in the rural case (case 6), the CAPE value is $0 \mathrm{~J} \mathrm{~kg}^{-1}$.

of case 1), whereas the CAPE value of the suburban area (case 2 minus case 1) increased by $36 \mathrm{~J} \mathrm{~kg}^{-1}(7 \%$ of case 1). The anthropogenic heat flux increased the CAPE value by $44 \mathrm{~J} \mathrm{~kg}^{-1}$ ( $4 \%$; case 3 minus case 4$)$, whereas the anthropogenic water vapor resulted in an $8 \mathrm{~J} \mathrm{~kg}^{-1}(1 \%$; case 3 minus case 5$)$ increase in the CAPE value. In the case of the variation in the initial profile, which reflected differences in the urban-rural thermal inertia, the CAPE decreased by $735 \mathrm{~J} \mathrm{~kg}^{-1}$ in the stable profile (case 8) compared to the near-neutral profile (case 3), which corresponded to a fivefold increase in the CAPE value in case 8. This result was true for the other stable cases, i.e., the CAPE values in the stable cases (cases 6-8) were lower than those in the near-neutral cases (cases 1-3). The reason for this was that the lifting condensation level (LCL) and LFC in the stable cases were greater than those in the near-neutral cases. For example, the LCL and LFC values were 1245 and $1695 \mathrm{~m}$ in case 8 , respectively. In contrast, in case 3, the LCL and LFC values were 1211 and $1213 \mathrm{~m}$, respectively. In the stable case, higher LCL primarily resulted from lower amount of water vapor at lower temperatures. High LFC values resulted in considerably small CAPE values in cases 6 and 7. Note that even in the trial calculations for cases 6-8 wherein the relative humidity in the lower initial profile was set to $99 \%$ ( $80 \%$ in the original cases $6-8$ shown in Fig. 3), CAPE was still lower than that in cases $1-3$. The CAPE values in these trial calculations were found to be $294 \mathrm{~J} \mathrm{~kg}^{-1}$ for the rural cover, 425 $\mathrm{J} \mathrm{kg}^{-1}$ for the suburban cover, and $753 \mathrm{~J} \mathrm{~kg}^{-1}$ for the urban land cover. The lower CAPE values in the stable cases could be partially due to the slower glowing speed of mixed layer. However, this would be a minor effect because in cases 6-8, the stable layer near the surface broke into the mixed layer by approximately 09 LST in the early morning and did not have much influence on the CAPE value at 12 LST.

\section{Discussion}

The results shown in Fig. 7 illustrate that depending on surface heating, the CAPE value in the city was greater than that in the rural countryside. Herein, we discuss two issues that are related to the universality 
of these results. The first is the spatial representativeness of the input surface heat flux. Urban areas have a complex mixture of various types of land covers, including buildings, roads, and parks. Therefore, the surface heat flux in urban areas varies across these land covers (Schmid et al. 1991). In this research, the observed diurnal variation in heat flux was used for the model input, where the maximum heat flux was $350 \mathrm{~W} \mathrm{~m}^{-2}$ at noon; however, other previous studies have shown different values. For example, Moriwaki and Kanda (2004) found a diurnal variation of 300 $\mathrm{W} \mathrm{m}{ }^{-2}$ at noon in summer. Their measurements were performed using the eddy covariance method across a 1-km residential area in Tokyo. Sugawara et al. (2015) reported a heat flux of $329 \mathrm{~W} \mathrm{~m}^{-2}$ as their morning average across a few tens of kilometers in the center of Tokyo, although this case study relied on sonde observations conducted during summer.

The input heat flux for the model could be greater than that for Tokyo. In contrast, the CAPE value was positively correlated to the input heat flux shown in Fig. 7. Furthermore, the evaluation of the urban influence on CAPE showed that it was also affected by the reference rural heat flux. Sugawara et al. (2015) showed that the heat flux over Tsukuba was $100 \mathrm{~W} \mathrm{~m}^{-2}$ smaller than that over Tokyo, which is in quantitative agreement with the difference in inputs between the suburban and rural areas considered herein (Fig. 6). Although Sugawara et al. (2015) conducted a case study, their conclusions help in validating our model inputs and results.

The second point related to the universality of our results is found in the initial condition. The CAPE value depends on the initial temperature profile and surface heating. Herein, we modeled two cases with different profiles in the lower layer; however, the upper layer also influences CAPE. Therefore, we checked the actual variation in the CAPE value with sonde observations, as summarized in Table 1. As shown in Fig. 8, CAPE was plotted as a function of surface air temperature, exhibiting the positive correlation of CAPE with air temperatures greater than $20^{\circ} \mathrm{C}$, although the scatter exceeded $1000 \mathrm{~J} \mathrm{~kg}^{-1}$. This variation, which could not be explained by the surface air temperature, is much larger than the urban influence shown in Fig. 7. Therefore, it can be concluded that the urban influence on CAPE may be smaller than that on the daily and spatial variations of atmospheric stratification.

Lee and Kimura (2001) numerically demonstrated the difference between terrain-induced convection and convection triggered at the boundary of different surfaces to determine the influence of topography and land cover on thermal convection. They found that thermal convection resulting from a $50 \%$ difference in the surface sensible heat flux would produce an effect similar to that produced by topographical convection, which is induced by a height difference in a 350-m terrain. Considering the actual situation in Tokyo, the urban heat flux was 2.3 times that of the rural heat flux (Fig. 6). However, mountains with an elevation of $600 \mathrm{~m}$ were located $50 \mathrm{~km}$ west of Tokyo; hence, the atmospheric convection induced by urban-rural heating variations may be canceled by the topographical convection in the greater Tokyo area.

\section{Conclusions}

In this study, we evaluated the influence of the excess of urban heat on atmospheric stability that can produce convective precipitation in the greater Tokyo area of Japan. This study focused on convective precipitation during the summer months. A simple methodology was used, which assumed a flat homogeneous ground surface with a single type of land cover. The CAPE values were calculated for different surface heat fluxes. We employed a simple idealized

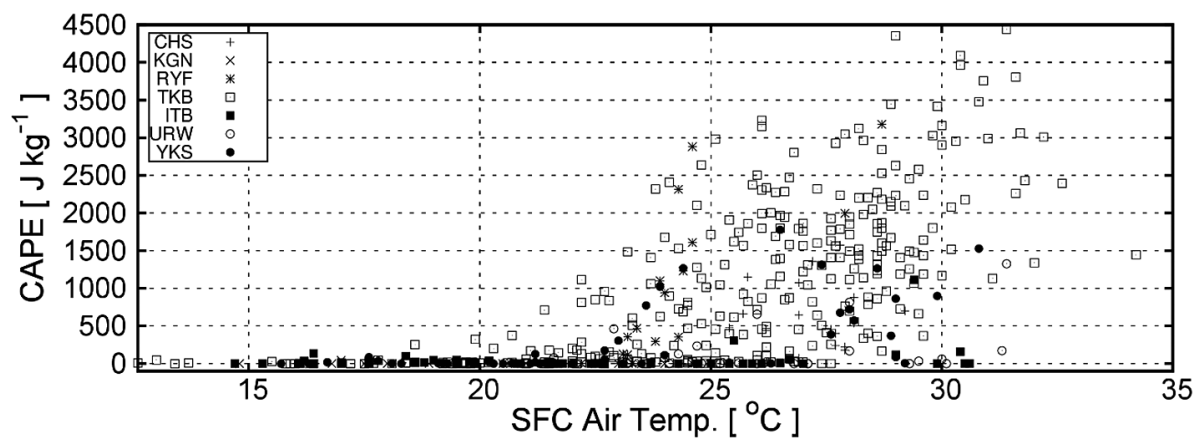

Fig. 8. Relation between the surface air temperature and CAPE. Location names were same as those defined in Fig. 2. 
situation using the ensemble average of the observed values for an initial profile of temperature and heat flux. The model calculations revealed that urban heat excess, which was $200 \mathrm{~W} \mathrm{~m}^{-2}$ higher than that in the rural area, increased the CAPE value by $75 \%$. The anthropogenic water vapor flux also increased the CAPE value, but its effect was nearly negligible (1\% change in CAPE). The neutral stratification in the urban area in the morning was due to the large thermal inertia in the urban canopy layer, yielding a CAPE value five times that of the rural value. These results showed that cities can cause favorable stratification of the atmosphere for convective precipitation, although the effect of the urban area appeared to be less important than the effects of topography or synoptic-scale disturbance.

This study focused on the thermal differences between the urban and rural areas. Other possible factors that influenced urban precipitation were the dynamic effects of high topographical surface roughness and the existence urban aerosols, which should be considered in future research.

\section{Acknowledgments}

We would like to thank Dr. Matsuki, Dr. Miyauchi, and Ms. Hirai from the Tokyo Kasei University, Dr. Nakajima from the Tokai University, and Dr. Narita from the Nippon Institute of Technology, Japan for assisting us in experimental observations. The Fortran code for the CAPE calculations (cape $7 \mathrm{~m}$ ) was provided by the Meteorological Research Institute of the Japan Meteorological Agency. The Urban Renaissance Agency, Public Enterprise Bureau of Saitama Prefecture, and Ortus Japan Co., Ltd. provided support for our observations. Ms. Araki helped with the calculations. The heat flux data from Tsukuba were provided by CRiED Tsukuba University. Sonde observations from the vessels Ryofu and Tsukuba were provided by the Japan Meteorological Agency. This study was supported by the Tokyo Metropolitan Area Convection Study for Extreme Weather Resilient Cities (TOMACS) program, which is supported by funds for the Integrated Promotion of Social System Reform and Research and Development (JST/MEXT).

\section{References}

Diem, J. E., I. Larkeisha, B., Coleman, P. A. Digirolamo, C. W. Gowens, N. R. Hayden, E. E. Unger, G. B. Wetta, and H. Williams, 2004: Comments on "Rainfall modification by major urban areas, observations from spaceborne rain radar on the TRMM satellite". $J$. Appl. Meteor., 43, 941-950.
Fujibe, F., K. Sakagami, K. Chiubachi, and K. Yamashita, 2002: Surface wind patterns preceding short-time heavy rainfall in Tokyo in the afternoon of midsummer days. Tenki, 49, 395-405 (in Japanese with English abstract).

Inoue, T., and F. Kimura, 2004: Urban effects on low-level clouds around the Tokyo metropolitan area on clear summer days. Geophys. Res. Lett., 31, L05103, doi: 10.1029/2003GL018908.

Inoue, T., S. Nakada, T. Terashima, and F. Kimura, 2004: Convective clouds over the urban area observed by a digital camera and satellites. Tenki, 51, 653-654 (in Japanese).

Kobayashi, F., M. Imai, H. Sugawara, M. Kanda, and H. Yokoyama, 2009: Generation of cumulonimbus first echoes in the Tokyo Metropolitan Region on midsummer days. Proc. 7th Int. Conf. on Urban Climate, Yokohama, Japan.

Kusaka, H., K. Nawata, A. Suzuki-Parker, Y. Takane, and N. Furuhashi, 2014: Mechanism of Precipitation Increase with Urbanization in Tokyo as Revealed by Ensemble Climate Simulations. J. Appl. Meteor. Climatol., 53, 824-839.

Kuwagata, T., N. Masuko, M. Sumioka, and J. Kondo, 1990: The daytime PBL heating process over complex terrain in central Japan under fair and calm weather conditions. Part II. Regional heat budget, convective boundary layer height and surface moisture availability. J. Meteor. Soc. Japan, 68, 639-650.

Lagouarde, J.-P., M. Irvine, J.-M. Bonnefond, C. S. B. Grimmond, N. Long, T. R. Oke, J. A. Salmond, and B. Offerle, 2006: Monitoring the sensible heat flux over urban areas using Large Aperture Scintillometry: Case study of Marseille city during the ESCOMPE experiment. Bound-Layer Meteor., 118, 449-476.

Lee, S.-H., and F. Kimura, 2001: Comparative studies in the local circulations induced by land-use and by topography. Bound.-Layer Meteor, 101, 157-182.

Macdonald, R. W., R. F. Griffiths, and D. J. Hall, 1998: An improved method for the estimation of surface roughness of obstacle arrays. Atmos. Environ., 32, 18571964.

Matheson, M. A., and Y. Ashie, 2008: The effect of changes of urban surfaces on rainfall phenomenon as determined by a non-hydrostatic mesoscale model. $J$. Meteor. Soc. Japan, 86, 733-751.

Ministry of the Environment Japan, 2003: Report on the environmental influence of urban heat island. (in Japanese). [Available at http://www.env.go.jp/air/report/ h15-02/.]

Moriwaki, R., and M. Kanda, 2004: Seasonal and diurnal fluxes of radiation, heat, water vapor, and carbon dioxide over a suburban area. J. Appl. Meteor., 43, 1700-1710.

Moriwaki, R., M. Kanda, H. Senoo, A. Hagishima, and T. Kinouchi, 2008: Anthropogenic water vapor emis- 
sions in Tokyo. Water Resour. Res., 44, W11424, doi: 10.1029/2007WR006624.

Ohashi, Y., and H. Kida, 2002: Local circulations developed in the vicinity of both coastal and inland urban areas: A numerical study with a mesoscale atmospheric model. J. Appl. Meteor, 41, 30-45.

Rosenfeld, D., and I. M. Lensky, 1998: Satellite-based insights into precipitation formation processes in continental and maritime convective clouds. Bull. Amer. Meteor. Soc., 79, 2457-2476.

Sato, N., and M. Takahashi, 2000: Long-term changes in the properties of summer precipitation in the Tokyo area. Tenki, 47, 643-648 (in Japanese with English abstract).

Sato, T., T. Terashima, T. Inoue, and F. Kimura, 2006: Intensification of convective precipitation systems over Tokyo urban area in summer season. Tenki, 53, 479484 (in Japanese with English abstract).

Schmid, H. P., H. A. Cleugh, C. S. B. Grimmond, and T. R. Oke, 1991: Spatial variability of energy fluxes in suburban terrain. Bound.-Layer Meteor., 54, 249-276.

Senoo, H., M. Kanda, T. Kinouchi, and A. Hagishima, 2004: Estimation of anthropogenic heat and vapor emission, and the impact on local meteorology. J. Japan Soc. Civ. Eng., 48, 169-174 (in Japanese with English abstract).

Shepherd, J. M., 2005: A review of current investigations of urban-induced rainfall and recommendations for the future. Earth Interact., 9, 1-27.

Shepherd, J. M., H. Pierce, and A. J. Negri, 2002: Rainfall modification by major urban areas: Observations from spaceborne rain radar on the TRMM satellite. J. Appl. Meteor, 41, 689-701.

Sugawara, H., K. Narita, and T. Mikami, 2001: Estimation of effective thermal property parameter on a heterogeneous urban surface. J. Meteor. Soc. Japan, 79, 11691181.

Sugawara, H., H. Aiso, R. Oda, and N. Seino, 2015: Comparison of daytime air heating amount between city and surrounding areas. J. Heat Isl. Inst. Int., 10, 1-5 (in Japanese with English abstract).

Takahashi, H., Y. Nakamura, and H. Suzuki, 2011: Frequency distribution of intense rainfall in the wards of Tokyo and its relationship with the spatial structure of building heights. J. Geogr., 120, 359-381

Tanaka, S., H. Sugawara, K. Narita, H. Yokoyama, I. Misaka, and D. Matsushima, 2011: Zero-plane displacement height in a highly built-up area of Tokyo. SOLA, 7, 93-96. 